\title{
P04-53 LB. Potent and broad HIV-specific neutralizing antibodies in infants are not associated with prevention of mother to infant HIV transmission J Lynch*1, R Nduati ${ }^{2}$, G John-Stewart ${ }^{3}$, B Richardson ${ }^{3}$ and J Overbaugh ${ }^{1}$
}

Address: ${ }^{1}$ Fred Hutchinson Cancer Research Center, Seattle, WA, USA, ${ }^{2}$ University of Nairobi, Nairobi, Kenya and ${ }^{3}$ University of Washington, Seattle, WA, USA

* Corresponding author

from AIDS Vaccine 2009

Paris, France. 19-22 October 2009

Published: 22 October 2009

Retrovirology 2009, 6(Suppl 3):P393 doi:10.1 186/1742-4690-6-S3-P393

This abstract is available from: http://www.retrovirology.com/content/6/S3/P393

(C) 2009 Lynch et al; licensee BioMed Central Ltd.

\section{Background}

Infants of women infected with HIV-1 are born with antibodies specific for the virus. In the non-human primate model, neutralizing antibodies (NAb) protect from SHIV/ SIV transmission, implying a role for such a response in candidate HIV vaccines. The setting of mother to child HIV transmission provides an opportunity to examine whether NAb provide protection from HIV infection in exposed humans.

\section{Methods}

Heterologous NAb breadth and potency were measured in week 0-1 postpartum plasma from breast-feeding infants $(\mathrm{N}=104)$ born to women with HIV-1 using pseudoviruses incorporating envelopes from 8 different variants in a single cycle infection assay. The plasma concentration inhibiting 50\% of virus (IC50) was determined for each virus/plasma pair and breadth/potency scores were defined. These were compared using the Mann-Whitney U test. A multivariate logistic regression model including maternal CD4 and viral load was used to determine the odds of infection and a Cox proportional hazards model was used to determine the impact of NAb potency and breadth on time to infection.

\section{Results}

In case-control analysis, the IC50 did not differ between infants who were or were not infected in the first $1.5(\mathrm{n}=$ 22), $6(n=25)$ or 24 months $(n=38)(p>0.5$ for each test). Potency $(\mathrm{p}=0.7)$ and breadth $(\mathrm{p}=0.49)$ of response did not differ between cases/controls. Neither potency nor breadth was associated with odds of infant infection (OR 1, p > 0.5). In cohort analysis, maternal viral load had the largest impact on time-to-infection $(\mathrm{HR}=1.97, \mathrm{p}$ $=0.011$ ), but neither neutralizing breadth nor potency appeared to play a role $(\mathrm{HR}=1, \mathrm{p}=0.5)$.

\section{Conclusion}

In this study of 104 infants at risk for breastfeeding HIV transmission, neither potent nor broad heterologous neutralizing antibodies affected transmission risk. These results suggest that the breadth of the antibody response, as defined by neutralization of a heterologous virus panel, does not predict protection from mother to child transmission. 